\title{
ROLE OF THORACOSCOPY IN UNDIAGNOSED PLEURAL EFFUSIONS
}

\author{
K. Raj Kumar', K. Surendar Reddy², K. Yugaveer ${ }^{3}$, K. Venu ${ }^{4}$
}

${ }_{1}^{1}$ Assistant Professor, Department of Pulmonary Medicine, Chalmeda Anand Rao Institute of Medical Sciences, Karimnagar, Telangana. ${ }^{2}$ Associate Professor, Department of Pulmonary Medicine, SVS Medical College and Hospital. ${ }^{3}$ Assistant Professor, Department of Pulmonary Medicine, KIMS, Narketpally, Nalgonda, Telangana. 4 Professor and HOD, Department of Pulmonary Medicine, KIMS, Narketpally, Nalgonda, Telangana.

ABSTRACT

\section{BACKGROUND}

Semi-rigid thoracoscopy is a safe and efficacious procedure in patients with undiagnosed pleural effusion.

Objectives-

1. To evaluate the role of thoracoscopy in undiagnosed pleural effusions.

2. To evaluate histopathological profile of undiagnosed pleural effusions.

\section{MATERIALS AND METHODS}

This prospective observational study was conducted on 50 patients with pleural effusion, who have been diagnosed between August 2009 and August 2011 at KIMS, Narketpally.

\section{RESULTS}

The common age group being 41 - 60 yrs. in 23 cases (46\%). There were 32 males (64\%) and 18 females (36\%) (Table 2). 26 patients (52\%) had right-sided pleural effusion and 19 (38\%) had left-sided pleural effusion and 5 (10\%) had bilateral pleural effusion. ADA is more than 60 in 16 cases (32\%) and less than 60 in 34 cases (68\%). Thoracic CT examination showed pleural nodularity in 12 patients (24\%). 25 patients (50\%) had tubercular pleural effusion, 5 patients (5\%) had chronic non-specific inflammation and 20 patients (45\%) had malignancy. Among malignancy, 14 patients (70\%) had adenocarcinoma, 1 patient (5\%) had mesothelioma and 5 patients $(25 \%)$ had squamous cell carcinoma.

\section{CONCLUSION}

Semi-rigid thoracoscopy is a safe and efficacious procedure in patients with undiagnosed exudative pleural effusions.

\section{KEYWORDS}

Pleural Biopsy, Pleural Effusion, Rigid Thoracoscope.

HOW TO CITE THIS ARTICLE: Kumar KR, Reddy KS, Yugaveer K, et al. Role of thoracoscopy in undiagnosed pleural effusions. J. Evolution Med. Dent. Sci. 2018;7(10):1268-1270, DOI: 10.14260/jemds/2018/289

\section{BACKGROUND}

Pleural effusion results from an abnormal collection of fluid due to excessive production or decreased pleural fluid absorption and can be transudative or exudative depending on the fluid composition. Pleural effusion is a common clinical problem with diverse aetiologies accounting for around $4 \%$ patients in pulmonary practice. ${ }^{[1,2]}$ The accurate diagnosis of pleural effusion is challenging, because even after thoracocentesis and/or closed pleural biopsy $25 \%-40 \%$ of pleural effusion remains undiagnosed.[3,4] Medical thoracoscopy also referred to as pleuroscopy is an endoscopic evaluation of the pleural space. It is a minimally invasive procedure that was first invented in 1910 by Hans Christian Jacobeus, a Swedish internist[5] who is also regarded as the "father of thoracoscopy." In the twentieth century, thoracoscopy was mainly used in the treatment of pulmonary tuberculosis (TB) and tubercular pleural adhesions. ${ }^{[6]}$ In recent years, thoracoscopy has gained a lot of interest and popularity

'Financial or Other Competing Interest': None.

Submission 13-01-2018, Peer Review 15-02-2018,

Acceptance 21-02-2018, Published 05-03-2018.

Corresponding Author:

Dr. K. Surendar Reddy,

Flat No. 905, TNR Vaishnovi Sikhaia Apartment,

SBH Colony, LB Nagar, Hyderabad-500074, Telangana.

E-mail: surendark918@gmail.com

DOI: $10.14260 /$ jemds/2018/289

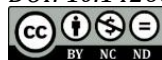

among pulmonary physicians, mainly in aetiological diagnosis of pleural effusions. The usefulness of thoracoscopy has also been extended in the evaluation of pneumothorax and empyema; in taking diagnostic biopsies from lung, diaphragm, mediastinum and pericardium for staging of lung cancers and malignant mesothelioma. Therapeutic procedures like pleurodesis and adhesiolysis may be done in preventing the recurrence of the pleural effusion and palliation of dyspnoea.[7]

The aim of our study was to evaluate the pathological profile of semi-rigid thoracoscopy in patients with undiagnosed exudative pleural effusions presenting to our centre.

\section{Objective}

1. To evaluate the role of thoracoscopy in undiagnosed pleural effusions.

2. To evaluate histopathological profile of undiagnosed pleural effusions.

\section{MATERIALS AND METHODS Study Setting}

The present study was carried out at Department of Pulmonary Medicine at KIMS, Narketpally, Nalgonda.

This prospective observational study was performed using a database with 50 patients who had been diagnosed with pleural effusion during August 2009 - August 2011. All the cases of pleural effusion that remained undiagnosed after 
initial and repeated biochemical and cytological analysis of the pleural fluid were enrolled in this study at our institution. Definition of undiagnosed pleural effusion was considered as the failure to achieve an aetiologic diagnosis by initial pleural fluid microscopic and biochemical analysis including protein, sugar, lactate dehydrogenase, Gram stain, acid-fast bacilli (AFB) smear and culture, pleural fluid adenosine deaminase (ADA) levels, and at least three pleural fluid cytologies negative for malignant cells or other definite causes.

\section{Procedure}

Patients were kept nil by mouth for 6 hours prior to the procedure. Intravenous access was achieved in the upper limb opposite to the side of thoracoscopy. Patients were then made to lie in lateral decubitus position with affected side facing upward and both the arms were placed above and below the head. Patient's vital parameters such as electrocardiogram, blood pressure and oxygenation were monitored continuously throughout the procedure. Thoracoscopy was carried out the port of site was usually 5 th or 6th intercostal space in midaxillary line. $1-2 \mathrm{~cm}$ sized incision was made and the subcutaneous tissue and muscles were bluntly dissected to reach the pleural cavity. Then a trocar with cannula was inserted through the chest wall, pleural fluid was aspirated and systemic exploration of the pleura and pleural cavity was done by rigid thoracoscope Hopkins (Karl Storz, Germany, $0^{\circ}, 49003$ AA). Site for second port for the purpose of pleural biopsies was made close to the first port; however, care was taken to avoid "fighting of instruments." Typically, 2 - 6 biopsies of the abnormal lesion inside the pleural cavity were taken by biopsy forceps under local anaesthesia by intercostal nerve block at the desired incision site and intravenous tramadol and midazolam were administered to increase patient's comfort without compromising respiration.

\section{Statistical Analysis}

Data was analysed by Statistical Package for Social Sciences (SPSS) Version 16.0. Categorical data was summarised by count and percentages. The association between categorical variables was done by Chi-square test. All the ' $p$ ' values less than 0.05 were considered as statistically significant.

\section{RESULTS}

50 patients with undiagnosed pleural effusion underwent semi-rigid thoracoscopy during the period August 2009 to August 2011, at our centre. The common age group being 4160 yrs. 23 cases (40\%) followed by 21 - 40 yrs. 15 cases (30\%), then more than 60 yrs. 8 cases $(16 \%)$ and less than 20 yrs. 4 cases (8\%). There were 32 males (64\%) and 18 females (36\%) (Table 1). 26 patients (52\%) had right-sided pleural effusion and 19 (38\%) had left-sided pleural effusion and 5 $(10 \%)$ had bilateral pleural effusion. ADA is more than 60 in 16 cases (32\%) and less than 60 in 34 cases (68\%) (Table 2). Thoracic CT examination showed Pleural nodularity in 12 patients (24\%). 25 patients (50\%) had tubercular pleural effusion, 5 patients (5\%) had chronic non-specific inflammation and 20 patients (45\%) had malignancy. Among malignancy 14 patients $(70 \%)$ had adenocarcinoma, 1 patient (5\%) had Mesothelioma and 5 patients (25\%) had squamous cell carcinoma (Table 3).

\begin{tabular}{|c|c|c|c|}
\hline Age in Years & Males & Females & Total \\
\hline$<20$ yrs. & $3(9 \%)$ & $1(5 \%)$ & $4(8 \%)$ \\
\hline $21-40$ yrs. & $10(31 \%)$ & $5(28 \%)$ & $15(30 \%)$ \\
\hline $41-60$ yrs. & $14(44 \%)$ & $9(50 \%)$ & $23(46 \%)$ \\
\hline$>60$ yrs. & $5(16 \%)$ & $3(17 \%)$ & $8(16 \%)$ \\
\hline Total & $32(100 \%)$ & $18(100 \%)$ & $\mathbf{5 0}(100 \%)$ \\
\hline \multicolumn{4}{|c|}{ Table 1. Demographic Distribution } \\
\hline
\end{tabular}

P value: 0.61 , Chi-square: 0.26

\begin{tabular}{|c|c|c|}
\hline Location & $\begin{array}{c}\text { X-Ray showing } \\
\text { Pleural Effusion }\end{array}$ & $\begin{array}{c}\text { CT showing } \\
\text { Pleural Nodules }\end{array}$ \\
\hline Right sided & $26(52 \%)$ & $5(42 \%)$ \\
\hline Left sided & $19(38 \%)$ & $3(25 \%)$ \\
\hline Bilateral & $5(10 \%)$ & $4(33 \%)$ \\
\hline Total & $\mathbf{5 0}(100 \%)$ & $\mathbf{1 2}(\mathbf{1 0 0} \%)$ \\
\hline \multicolumn{2}{|c|}{ Table 2. Radiological Distribution } \\
\hline
\end{tabular}

P-value: 0.03 (Significant), Chi-square: 4.246.

\begin{tabular}{|c|c|c|c|}
\hline Type & ADA $<60$ & ADA $>60$ & \begin{tabular}{|l|} 
No. of Cases \\
\end{tabular} \\
\hline 1. Malignancy & $20(59 \%)$ & $0(0 \%)$ & $20(45 \%)$ \\
\hline $\begin{array}{l}\text { a. Squamous Cell } \\
\text { Carcinoma }\end{array}$ & $5(25 \%)$ & 0 & $5(25 \%)$ \\
\hline b. Adenocarcinoma & $14(70 \%)$ & 0 & $14(70 \%)$ \\
\hline $\begin{array}{c}\text { c. Malignant } \\
\text { mesothelioma }\end{array}$ & $1(5 \%)$ & 0 & $1(5 \%)$ \\
\hline $\begin{array}{c}\text { 2. Chronic non-specific } \\
\text { inflammation }\end{array}$ & $3(9 \%)$ & $2(13 \%)$ & $5(5 \%)$ \\
\hline 3. Tuberculosis & $11(32 \%)$ & $14(87 \%)$ & $25(50 \%)$ \\
\hline Total & $34(100 \%)$ & $16(100 \%)$ & $50(100 \%)$ \\
\hline
\end{tabular}

P-value: 0.00027 (Significant), Chi-square: 13.23.

\section{DISCUSSION}

Pleural effusions are common problem in the pulmonary practice. If a pleural biopsy specimen is needed, a physician must usually choose between a blind pleural biopsy and a Pleuroscopic biopsy. In our institute we did pleuroscopy, because most of our patients were referred (> 85\%) and they are already on anti-TB drugs for more than 3 weeks duration with no clinical improvement. Most of our study belonged to the patients of age group between $41-60$ yrs. contributes to 23 cases (46\%) with a mean age of 50.5 yrs., which is comparable to study conducted by Loganathannattusamy et al, where it is 50.9 yrs. ${ }^{(8)}$ and VG Prabhu et al where it is 50.5 yrs.(9)

In this study, males (64\%) are more in number than females (36\%), which is comparable to studies conducted by Loganathannattusamy et $\mathrm{al}^{(8)}$ where males contributed to $65.4 \%$ and females $35.4 \%$ and VG Prabhu et al(9) where males contributed to $80.8 \%$ and females $19.2 \%$.

In this study, right-sided pleural effusions (52\%) are more common compared to left-sided effusions (38\%) which is comparable to study conducted by Loganathannattusamy et al(8) where right-sided effusions contribute to $52.08 \%$ and left-sided effusions contribute to $47.92 \%$.

Thoracic CT examination showed pleural nodularity in 12 patients (24\%), which is comparable to study conducted by Loganathannattusamy et al(8) in which $29.79 \%$ showed pleural nodularity. 


\section{Jemds.com}

25 patients $(50 \%)$ had tubercular pleural effusion, 5 patients (5\%) had chronic non-specific inflammation and 20 patients (45\%) had malignancy. Among malignancy 14 patients $(70 \%)$ had adenocarcinoma, one patient $(5 \%)$ had mesothelioma and 5 patients (25\%) had squamous cell carcinoma which is comparable to study conducted by Loganathannattusamy et al(8) which showed that malignancy $(62.5 \%)$ is the common cause of effusion, among which adenocarcinoma $(35.42 \%)$ is the most common cause. Out of 50 cases, in 45 cases diagnosis was confirmed with thoracoscopy.

\section{CONCLUSION}

Medical thoracoscopy should be considered in all patients with undiagnosed exudative pleural effusions, particularly those with lymphocytic predominant effusions where underlying malignant process is strongly suspected and where an initial clinical diagnosis was $\mathrm{TB}$, but showing poor response to specific therapy.

\section{REFERENCES}

[1] Ansari T, Idell S. Management of undiagnosed persistent pleural effusions. Clin Chest Med 1998;19(2):407-17.

\section{Original Research Article}

[2] Dev D, Basran GS. Pleural effusion: a clinical review. Monaldi Arch Chest Dis 1994;49(1):25-35.

[3] Light RW. Clinical practice. Pleural effusion. N Engl J Med 2002;346(25):1971-7.

[4] Poe RH, Israel RH, Utell MJ, et al. Sensitivity, Specificity and predictive value of closed pleural biopsy. Arch Intern Med 1984;144(2):325-8.

[5] Jacobaeus HC. Fibreoptic laparoscopy and thoracoscopy. Beitr Klin Tuberk 1913;25:1-170.

[6] Hucker J, Bhatnagar $\mathrm{NK}$, al-Jilaihawi $\mathrm{AN}$, et al. Thoracoscopy in the diagnosis and management of recurrent pleural effusions. Ann Thorac Surg 1991;52(5):1145-7.

[7] Hashemzadeh S, Hashemzadeh K, Mamaghani K, et al. Pleurodesis by erythromycin, tetracycline, Aerosil ${ }^{\mathrm{TM}}$ 200, and erythromycin plus Aerosil ${ }^{\mathrm{TM}} 200$ in a rat model: a preliminary study. Daru 2012;20(1):79.

[8] Nattusamy L, Madan K, Mohan A, et al. Utility of semirigid thoracoscopy in undiagnosed exudative pleural effusion. Lung India 2015;32(2):119-26.

[9] Prabhu VG, Narasimhan R. The role of pleuroscopy in undiagnosed exudative pleural effusion. Lung India 2012;29(2):128-30. 